Article

\title{
Effects of Additional Xylanase on Saccharification and Ethanol Fermentation of Ammonia-Pretreated Corn Stover and Rice Straw
}

\author{
Seung Hyeon Park ${ }^{1}$, Thi Thu Huong Pham ${ }^{2}$ and Tae Hyun Kim ${ }^{1, *(\mathbb{D})}$ \\ 1 Department of Materials Science and Chemical Engineering, Hanyang University, Ansan, \\ Gyeonggi-do 15588, Korea; tmdgus5409@naver.com \\ 2 Faculty of Technology, Van Lang University, Ho Chi Minh City 70000, Vietnam; phamhuong10sh@gmail.com \\ * Correspondence: hitaehyun@hanyang.ac.kr; Tel.: +82-31-400-5222
}

Received: 30 May 2020; Accepted: 21 August 2020; Published: 3 September 2020

\begin{abstract}
Synergistic effect of cellulase and hemicellulase (xylanase) was evaluated because lignocellulosic material is a heterogeneous complex of cellulose and hemicellulose. Various effects of HTec 2 addition on enzymatic saccharification and fermentation were evaluated using two different substrates such as corn stover and rice straw. Corn stover and rice straw were pretreated by the LMAA (low-moisture anhydrous ammonia) method at the preselected same conditions $\left(90^{\circ} \mathrm{C}, 120 \mathrm{~h}\right.$, moisture content $=50 \%, \mathrm{NH}_{3}$ loading $=0.1 \mathrm{~g} \mathrm{NH}_{3} / \mathrm{g}$ ). It was observed that the enzymatic saccharification yield of pretreated corn stover $(76.4 \%$ for glucan digestibility) was higher than that of pretreated rice straw (70.9\% for glucan) using CTec2 cellulase without HTec2 addition. Glucan digestibility of pretreated corn stover was significantly increased from $76.4 \%$ to $91.1 \%$ when the HTec2/CTec2 (v/v) increased from 0 to 10 . However, it was interesting that the ethanol production was decreased from $89.9 \%$ to $76.3 \%$ for SSF and $118.0 \%$ to $87.9 \%$ for SSCF at higher HTec2/CTec2. As the glucan loading increased from $2.0 \%$ to $7.0 \%$, the ethanol yields of both SSF and SSCF were decreased from $96.3 \%$ to $88.9 \%$ and from $116.6 \%$ to $92.4 \%$, respectively. In addition, the smallest inoculum size (optical density of 0.25 ) resulted in the highest ethanol production $(20.5 \mathrm{~g} / \mathrm{L})$.
\end{abstract}

Keywords: pretreatment; inoculum size; high-solid fermentation; enzymatic saccharification; simultaneous

\section{Introduction}

The world economy is now largely dependent on fossil energy sources. Coal and crude oil are currently main sources of energy used for the productions of fuels, chemicals, power, and so on [1]. The world's population is growing, so global energy use is increasing rapidly every year [2]. Depending on the use of fossil sources, greenhouse gas emissions are increasing every year. Therefore, various alternative sources of energy such as solar, wind, and biomass have attracted attention and are regarded as renewable sources. Among those sources, lignocellulosic biomass has been studied as an important resource that can be converted into liquid transportation fuels (ethanol and butanol) and various industrial biochemical products by utilizing main components of biomass such as cellulose, hemicellulose, and lignin [3-5]. In the past, sugar and starch obtained from sugarcane and corn grain have been primary source of fuel ethanol production, termed as the first-generation biomass and fuel, respectively [6]. However, these resources conflict with food use and have limited availability. On the contrary, lignocellulosic material, the second-generation biomass, is more abundant and less expensive than the first-generation biomass. In addition, lignocellulosic material has potential to be a more viable source for the biochemical industry because it consists of various components, which can be converted into various fuels and chemicals. In general, the production of foods and animal 
feeds generates more tons of lignocellulosic material as a by-product every year [2]. However, effective utilization of lignocellulosic material is much more difficult than that of the first generation biomass because lignocellulosic material has a very different physical structure and chemical composition than sugar and starch; for example, the plant cell wall of lignocellulosic material contains three major biopolymers including cellulose, hemicellulose, and lignin. Cellulose is a linear chain of many $\beta$ $(1 \rightarrow 4)$-D-glucose units, and the structure is crystalline and the $\beta(1 \rightarrow 4)$ linkage is difficult to break [7]. Hemicellulose is highly branched heteropolymers composed of 5-carbon (xylose and arabinose) and 6-carbon sugars (glucose, galactose, and mannose) [8]. Lignin is a three-dimensional and amorphous polymer consisting of three different phenyl-propane precursor monomer units (guaiacyl (G), syringyl $(\mathrm{S})$, and $p$-hydroxylphenyl $(\mathrm{H})$ ) which are particularly difficult to biodegrade, which is most resistant to enzymatic degradation [9].

In order to effectively convert lignocellulosic material to fuels and chemicals, it requires typically four essential steps including pretreatment, enzymatic saccharification, fermentation, and product recovery $[10,11]$. Among them, pretreatment is the first and essential step to open up the rigid structure of lignocellulosic material, and then enzymatic saccharification depolymerize cellulose and hemicellulose in the pretreated biomass to fermentable sugars, which are considered as the most cost incurring steps in bioconversion process [12]. Recently various chemical pretreatment methods have been developed for lignocellulosic biomass to enhanced saccharification and fermentation yields. However, each method has advantages and disadvantages depending on reaction conditions and catalysts. For example, ionic liquid (IL) pretreatment uses mild condition like a LMAA, which is effective for solubilization of the plant cell wall, while IL is much more expensive than ammonia. Low temperature steep delignification (LTSD) was reported as very effective for high conversion rate and yield and easy to recover chemicals, while it can generate some toxic products. Compared to other conventional pretreatment methods, LMAA and LTSD use low concentrations of non-toxic chemicals. In addition, cosolvent enhanced lignocellulosic fractionation (CELF) was recently proposed and it claimed very high fermentable sugar recovery $(95 \%)$. However, as compared to LMAA, CELF requires a more severe condition (high temperature), which results in toxic byproducts like furfural, 5-hydroxymethylfurfural, levulinic acid, etc. [13]

Thus, it was suggested that the development of an effective enzymatic saccharification process is most important for effective conversion of lignocellulosic material [8]. The combined effects of cellulase and hemicellulase, along with adequate enzyme dosages, are the key factor; however, for a successful and economically viable bioconversion process, the pretreatment method should be developed taking into account the important factors of the enzymatic saccharification process such as enzyme dosages and ratios [14]. The effects of cellulase and hemicellulase on sugar and ethanol productions were not vigorously investigated even though they are closely related to each other; therefore, we think it is reasonable if two processes (pretreatment and enzymatic hydrolysis) are studied as a combined series of process.

In our laboratory, various pretreatment methods using ammonia as a pretreatment reagent have been investigated because ammonia has numerous advantages as a pretreatment reagent; for example, it is highly effective for delignification, it has a strong swelling effect, and it preserves cellulose and hemicellulose well [15-17]. The low-moisture anhydrous ammonia (LMAA) method can significantly improve the enzymatic saccharification yield of lignocellulosic material with low ammonia and water inputs. Moreover, the LMAA pretreatment method preserves all cellulose and hemicellulose in the solid, which has been proven to be effectively hydrolyzed by commercial cellulase $[18,19]$.

Saccharification and fermentation can be combined for effective conversion of pretreated biomass into ethanol. There are several process options for effective bioconversion of biomass including (1) the separate hydrolysis and fermentation (SHF) process as the simple process scheme, (2) simultaneous saccharification and fermentation (SSF), and (3) simultaneous saccharification and co-fermentation (SSCF). Although commercial cellulase is a mixture of cellulase and hemicellulase (mainly xylanase), it typically has insufficient hemicellulase activity, which is not enough to hydrolyze a high level of 
hemicellulose in the LMAA-treated solid. In this study, it was hypothesized that addition of xylanase could significantly improve the total saccharification yield of the LMAA-treated biomass due to its synergistic effect with cellulase activity $[19,20]$. The effect of additional xylanase on the ethanol yield in both SSF and SSCF was evaluated. Two representative lignocellulosic materials, corn stover and rice straw, were compared and used as substrates for ethanol production, which were pretreated by the LMAA method under identical conditions $\left(90^{\circ} \mathrm{C}, 120 \mathrm{~h}\right.$, and $\mathrm{L} / \mathrm{S}=1.0, \mathrm{NH}_{3}$ loading $=0.1 \mathrm{~g} / \mathrm{g}$-biomass $)$, which were selected as the best conditions in the previous study $[17,18]$. The enzymatic digestibility of LMAA-treated biomass was measured upon various additional xylanase loadings, keeping cellulase enzyme loading at constant. The SSF was carried out with Saccharomyces cerevisiae $\left(D_{5} A\right)$, and the SSCF was carried out with recombinant Escherichia coli (K011) with different solid loadings, xylanase loadings, and cell inoculum sizes.

\section{Materials and Methods}

\subsection{Feedstock}

Two different lignocellulosic materials, corn stover and rice straw, were used in this study. Corn (Zea maysvar. saccharata) and rice (Oryza sativa) were grown and harvested in Korea in 2015 and 2014, respectively. The residues, including stalks, straws, and leaves (corn stover and rice straw with moisture content of $\sim 8.0 \mathrm{wt} . \%$ ), were ground and sieved to a nominal size of 9-35 Tyler mesh size (0.5-2.0 $\mathrm{mm}$ of nominal sieve opening) and placed in the tight-sealed plastic container.

The composition of biomass was determined following the laboratory analytical procedure (LAP) described by the National Renewable Energy Laboratory (NREL, Golden, CO, USA) [21]. The composition of the corn stover was $31.5 \mathrm{wt} . \%$ glucan, $22.5 \mathrm{wt} . \%$ xylan, $2.1 \mathrm{wt} . \%$ galactan, $1.7 \mathrm{wt} . \%$ arabinan, $18.0 \mathrm{wt} . \%$ lignin (acid insoluble lignin (AIL) + acid soluble lignin (ASL)), $0.7 \mathrm{wt} . \%$ sucrose, $0.7 \mathrm{wt} . \%$ ash, and $15.2 \mathrm{wt} . \%$ other extractives. The composition of rice straw was $34.8 \mathrm{wt} . \%$ glucan, $20.1 \mathrm{wt} . \%$ xylan, $1.8 \mathrm{wt.} \%$ galactan, $2.3 \mathrm{wt} . \%$ arabinan, $17.3 \mathrm{wt} . \%$ lignin (AIL + ASL), $0.6 \mathrm{wt} . \%$ sucrose, $8.4 \mathrm{wt} . \%$ ash, and $16.4 \mathrm{wt} . \%$ other extractives.

\subsection{Enzymes}

Cellulase Cellic ${ }^{\circledR}$ CTec2 (batch no. VCP10006) and hemicellulase Cellic ${ }^{\circledR}$ HTec2 (batch no. VHN00002) were obtained from Novozymes Inc. (Bagsvaerd, Denmark). The average activity of cellulase was measured to be 92.7 filter paper unit (FPU)/mL and the protein content following the Bradford assay was determined to be $76.1 \mathrm{mg}$-protein $/ \mathrm{mL}$. The average activity and protein concentrations of HTec2 following Ghose and Bisaria (1987) were measured as $294.3 \mu \mathrm{mol} / \mathrm{mL}$ and $101.0 \mathrm{mg}$-protein/mL, respectively [22].

\subsection{Pretreatment}

Ground feedstock was moisturized by adding deionized (DI) water to keep moisture content of $50 \mathrm{wt} . \%$ (1.0 g- $\mathrm{H}_{2} \mathrm{O} / \mathrm{g}$-dry biomass) and then, for homogenization, placed them in the rotating tumbler for $1 \mathrm{~h}$. Anhydrous ammonia was introduced to the batch reactor packed with moisturized biomass, so called the ammoniation step. The target ammonia loading was $0.1 \mathrm{~g}-\mathrm{NH}_{3} / \mathrm{g}$-biomass after reaction and residence time was kept for $10 \mathrm{~min}$.

For ammoniation, $20 \mathrm{~g}$ moisturized biomass $\left(10 \mathrm{~g}\right.$ biomass $\left.+10 \mathrm{~g} \mathrm{H}_{2} \mathrm{O}\right)$ was packed in a tubular reactor with an internal volume of $150 \mathrm{~mL}(2.54 \mathrm{~cm} \mathrm{ID} \times 29.97 \mathrm{~cm} \mathrm{~L})$. An ammonia gas cylinder was connected to the bottom of the reactor. The top of the reactor was connected to the fume hood for $\mathrm{NH}_{3}$ ventilation. After putting and locking the biomass inside the reactor, $\mathrm{NH}_{3}$ was purged through the reactor for $10 \mathrm{~s}$. Then, the vent was closed. $\mathrm{NH}_{3}$ gas was introduced into the reactor from the bottom. The pressure was maintained at 15 psi to achieve the desired $\mathrm{NH}_{3}$ loading of $0.1 \mathrm{~g} \mathrm{NH}_{3} / \mathrm{g}$ oven dry weight (ODW) biomass. The valve in the top of the reactor was closed for $20 \mathrm{~min}$ and was then opened 
to the atmosphere in the fume hood. After ammoniation, biomass was transferred to a tightly capped plastic container; biomass was mixed carefully and weighed.

After the ammoniation step, the ammoniated biomass was subjected to the heat treatment step at elevated temperature $\left(90^{\circ} \mathrm{C}\right)$ for five different durations $(24,48,72,96$, and $120 \mathrm{~h})$ in the forced convection oven. After the heat treatment step, the reactors were cooled down for $15 \mathrm{~min}$ in the air. Subsequently, excess ammonia was evaporated in the air-the treated biomass was transferred into a stainless tray and was placed in the fume hood for the evaporation of ammonia at room temperature for $1.0 \mathrm{~h}$. Moisture content of the pretreated sample should not drop below $30 \%$ because over-drying may affect the enzyme hydrolysis by causing the collapse of the pretreated structure so it was carefully monitored. LMAA-treated samples were then collected and stored for analysis and further experiments.

\subsection{Enzymatic Digestibility}

Enzymatic digestibility of rice straw and corn stover was determined in duplicate following the NREL-LAP [23]. The LMAA-treated corn stover and rice straw were digested under identical test conditions. Cellulase (CTec2) and xylanase (HTec2) were used for the saccharification step. The hydrolysis reactions were conducted in the screw-capped $250 \mathrm{~mL}$ Erlenmeyer flasks with $100 \mathrm{~mL}$ of total working volume containing $1 \% w / v$ glucan loading. LMAA-pretreated corn stover and rice straw under $90^{\circ} \mathrm{C}$ for $120 \mathrm{~h}$ were used as substrates. Sodium citrate buffer $(0.05 \mathrm{M}, \mathrm{pH}=4.8)$ was used with the addition of $40 \mathrm{mg} / \mathrm{L}$ tetracycline and $30 \mathrm{mg} / \mathrm{L}$ cyclohexamide. Cellulase loading of 15 FPU/g-glucan with various dosages of xylanase: HTec2/CTec2 volume ratio was 0, 1.0, 1.5, 2.0, 5.0 and 10. The digestibility tests were conducted under conditions of $50{ }^{\circ} \mathrm{C}$ and $150 \mathrm{rpm}$ in a shaking incubator (model: VS-8480SFN, Vision Scientific Co., Ltd., Daejeon, Korea). Sampling was done periodically; glucan and xylan digestibilities were defined as the percentage of theoretical glucan or xylan released from 0 to $120 \mathrm{~h}$ of digestion. The following equations were used for the calculations for enzymatic digestibility:

$$
\begin{aligned}
\text { Glucan digestibility }[\mathrm{wt} \%] & =\frac{\text { Total released glucose }(\mathrm{g}) \times 0.9}{\text { Initial glucan loading }(\mathrm{g})} \times 100 \\
\mathrm{XMG} \text { digestibility }[\mathrm{wt} \%] & =\frac{\text { Total released } \mathrm{xmg}(\mathrm{g}) \times 0.88}{\text { Initial XMG loading }(\mathrm{g})} \times 100
\end{aligned}
$$

In the above equations, XMG is defined as the sum of xylan, mannan, and galactan, while xmg refers to the sum of xylose, mannose, and galactose, and 0.88 and 0.9 are the conversion factors for $\mathrm{XMG}$ and glucan in the substrate to monomeric xmg and glucose, respectively.

The untreated samples and Avicel ${ }^{\circledR}$ PH-101 (catalog number 11,365, lot number BCBJ0229V, Sigma Aldrich co. ltd. St. Louis, MO, USA) were subjected to the digestibility under the same condition as control and reference.

\subsection{Simultaneous Saccharification and Fermentation (SSF) and the Simultaneous Saccharification and Co-Fermentation (SSCF)}

The SSF and SSCF processes were conducted following the NREL-LAP [24]. For the SSF test, colonies of S. cerevisiae (D $\left.\mathrm{D}_{5} \mathrm{~A}\right)\left(\mathrm{ATCC}^{\circledR}{ }^{\circledR}\right.$ 200062, American Type Culture Collection (ATCC), Manassas, VA, USA) on solid medium were used to inoculate $100 \mathrm{~mL}$ sterile YPD $(10 \mathrm{~g} / \mathrm{L}$ yeast extract, $20 \mathrm{~g} / \mathrm{L}$ peptone, $20 \mathrm{~g} / \mathrm{L}$ dextrose) in $250 \mathrm{~mL}$ flasks. The inoculum was incubated in a shaking incubator (model: VS-8480SFN, Vision Scientific Co., Ltd., Daejeon, Korea) at $30{ }^{\circ} \mathrm{C}$ and $150 \mathrm{rpm}$ for $10-14 \mathrm{~h}$. The microbial cells were harvested by centrifugation (model: MF 80, Hanil Science Co., Ltd., Gimpo, Korea) at $3000 \mathrm{rpm}$ for $2 \mathrm{~min}$ duration, then decantation of the supernatant was performed. The cells were re-suspended in sterilized DI water via vortex spinner. Re-suspended cells were diluted to $1 / 10$ of the volume of water before adding it to the inoculum, then to the experimental flasks with a starting OD (optical density) of 0.50. For the SSCF test, a similar procedure was used to prepare 
the recombinant E. coli (K011) (ATCC ${ }^{\circledR}$ 55124) inoculum as well, except that sterile LB (Luria-Bertani; $10 \mathrm{~g} / \mathrm{L}$ Tryptone, $5 \mathrm{~g} / \mathrm{L}$ Yeast Extract, $5 \mathrm{~g} / \mathrm{L} \mathrm{NaCl}$ ) medium was used.

SSF and SSCF tests were conducted using LMAA-treated corn stover and rice straw as substrates and CTec2 and HTec2. Both SSF and SSCF tests were performed in the 250-mL flasks with rubber stoppers and incubated at $37{ }^{\circ} \mathrm{C}$ and $150 \mathrm{rpm}$. The initial solid loading was $3 \% \mathrm{w} / \mathrm{v}$ glucan (= $\sim 9 \%$ total biomass loading). The working volume was $100 \mathrm{~mL}$. The enzyme loading was $15 \mathrm{FPU} / \mathrm{g}$-glucan of cellulase $\mathrm{CTec} 2$, and the HTec2:CTec2 volume ratio was 0.0, 1.5, 2.0, and 10.0. The $\mathrm{pH}$ of SSF with S. cerevisiae $\left(\mathrm{D}_{5} \mathrm{~A}\right)$ was adjusted to around $\mathrm{pH} 5.0$ at the beginning, and the $\mathrm{pH}$ for the SSCF with E. coli (K011) was set around 7.0.

Ethanol yield (\% of theoretical maximum) was calculated as follows:

$$
\text { Ethanol yield }(\% \text { of the theoretical max })=\frac{\text { Total ehtanol produced }(\mathrm{g}) \text { in reactor }}{\text { Initial sugar }(\mathrm{g}) \text { in reactor } \times 0.511} \times 100
$$

The initial sugars in the above equation are glucose and xylose or just glucose, which would be completely produced hydrolysis of glucan and xylan in untreated corn stover and rice straw used in the SSF and SSCF experiment.

For high-solid fermentations in fed-batch SSF and SSCF operation modes, the whole test procedure was similar, but the initial glucan loading was $2.0 \%(\mathrm{~g} / \mathrm{mL})$. After every $12 \mathrm{~h}$ of SSF and SSCF, the substrate was added up to $4.0,5.0,6.0$, and $7.0 \%$ with the addition of enzymes.

\subsection{Compositional Analysis}

The composition of untreated and pretreated corn stover and rice straw was analyzed following the LAP of the NREL [21]. (The analysis included the determination of lignin (acid soluble lignin and acid insoluble lignin), extractives, carbohydrates (monomeric sugars), and ash content. Carbohydrates were determined by a high performance liquid chromatography (HPLC, Model LC-10A, Shimadzu Inc., Kyoto, Japan) with a Bio-Rad Aminex HPX-87P (catalog number 1,250,098, Bio-Rad Inc., Hercules, CA, USA) column and a refractive index detector (RID-10A, Shimadzu Inc., Kyoto, Japan). The monomeric sugars and ethanol concentrations in the samples obtained from digestibility and fermentation tests were measured by a HPX-87H column (catalog number 1,250,140, Bio-Rad Inc., Hercules, CA, USA). Sulfuric acid $\left(\mathrm{H}_{2} \mathrm{SO}_{4}, 5.0 \mathrm{mM}\right)$, as the mobile phase, was pumped into the HPLCat a $0.6-\mathrm{mL} / \mathrm{min}$ flow rate and $60^{\circ} \mathrm{C}$ column temperature.

\section{Results and Discussion}

\subsection{Enzymatic Saccharification of LMAA-Treated Corn Stover and Rice Straw}

In this study, the effect of reaction time of the LMAA on the enzymatic saccharification for two different feedstocks, including corn stover and rice straw, was compared and evaluated. Among the reaction parameters in the pretreatment such as $\mathrm{NH}_{3}$ loading, moisture content $\left(\mathrm{H}_{2} \mathrm{O}\right.$ loading per gram biomass), reaction temperature, and reaction time, only reaction time varied from 24 to $120 \mathrm{~h}$, keeping other conditions at constant; i.e., five different reaction times (24-120 h) were employed at $90{ }^{\circ} \mathrm{C}$, using corn stover and rice straw with $0.1 \mathrm{~g} \mathrm{NH}_{3} / \mathrm{g}$ ODW biomass and moisture content of $50 \mathrm{wt} . \%$.

Digestibilities were determined during $120 \mathrm{~h}$ of hydrolysis time with $15 \mathrm{FPU} / \mathrm{g}$-glucan cellulase $\mathrm{CTec} 2$ and the addition of HTec2 with HTec2/CTec2 ratio is $1.5(v / v)$. The digestibility test results were summarized in Figure 1a,b. An increase of pretreatment time from 24 to $120 \mathrm{~h}$ did not result in significant improvement on enzymatic digestibility of corn stover and rice straw. The glucan digestibility (at $72 \mathrm{~h}$ of hydrolysis) of LMAA-treated corn stover and rice straw increased from $79.1 \%$ to $82.8 \%$ and $70.4 \%$ to $71.5 \%$, respectively when the reaction time was increased from 24 to $120 \mathrm{~h}$. According to the results in Figure 1, LMAA pretreatment for extended reaction time longer than $24 \mathrm{~h}$ has no significant effect on enzymatic digestibility with 15 FPU/g-glucan enzyme loading. 


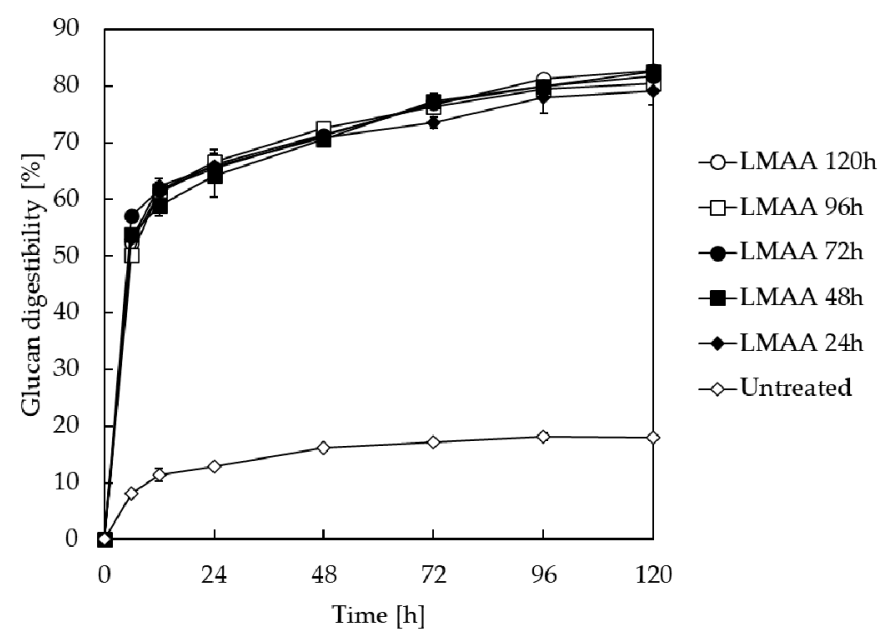

(a)

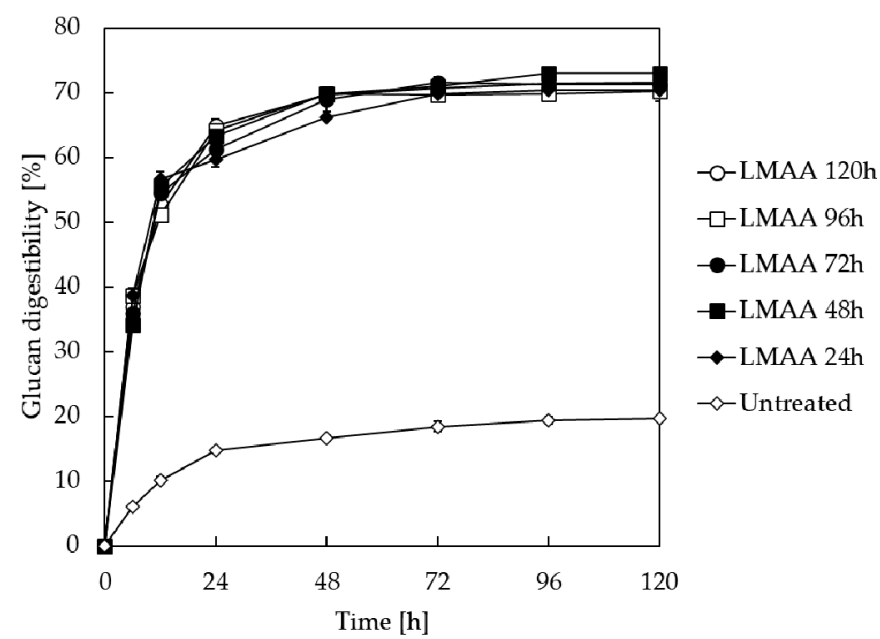

(b)

Figure 1. Effects of various reaction time of LMAA treatment on the enzymatic hydrolysis for (a) LMAA-treated corn stover and (b) LMAA-treated rice straw. Pretreatment reaction conditions: 24-120 h, $90^{\circ} \mathrm{C}$, ammonia loading of $0.1 \mathrm{~g} \mathrm{NH}_{3} / \mathrm{g}$ ODW, moisture content of $50 \mathrm{wt} . \%$.

\subsection{Effects of LMAA Pretreatment on Chemical Compositions of Corn Stover and Rice Straw}

It should be noted that the main purpose of this study was not to determine the pretreatment conditions for an economically viable process, but to evaluate the effect of additional xylanase on enzymatic hydrolysis and fermentation. Based on our previous reports $[17,18]$, it was found that the LMAA treatment of corn stover at $80-90{ }^{\circ} \mathrm{C}$ and $48-84 \mathrm{~h}$ resulted in enhanced saccharification yields. In this study, the longer reaction time of $120 \mathrm{~h}$ and reaction temperature of $90^{\circ} \mathrm{C}$ were chosen to render sufficient pretreatment effects for two different biomass. The carbohydrate and lignin contents of LMAA-treated corn stover and rice straw were presented in Table 1.

The glucan content in the untreated corn stover and rice straw were $31.6 \%$ and $34.7 \%$, respectively. The XMG (xylan + mannan + galactan) contents were $22.6 \%$ and $20.2 \%$, respectively. Other sugars account for only a small portion of the total sugar in the biomass. Sugar retention of LMAA-pretreated corn stover and rice straw was nearly $100 \%$ and it did not change the lignin content significantly. These results were in accordance with our previous reports that LMAA pretreatment is efficient to preserve both glucan and XMG in the treated solid [17]. In addition, it was confirmed by HPLC analysis of pretreatment liquid sample that the relatively mild temperature of LMAA treatment at $90^{\circ} \mathrm{C}$ did not 
result in the formation of degradation products such as furfural and 5-HMF (hydroxymethylfurfural) that could be inhibitory for enzymatic hydrolysis and microbial fermentation. This was also in line with the previous report that LMAA pretreatment did not have any weight loss because there was no washing step after the pretreatment [17].

Table 1. Chemical compositions of untreated and LMAA-treated corn stover and rice straw.

\begin{tabular}{cccccc}
\hline Component & \multicolumn{2}{c}{ Corn Stover } & \multicolumn{2}{c}{ Rice Straw } \\
\hline & & Untreated & LMAA-Treated & Untreated & LMAA-Treated \\
\hline Glucan & {$[\%]$} & $31.6 \pm 0.3$ & $31.5 \pm 0.4$ & $34.7 \pm 0.5$ & $34.8 \pm 0.3$ \\
$\mathrm{XMG}^{a}$ & {$[\%]$} & $22.6 \pm 0.9$ & $22.5 \pm 0.8$ & $20.2 \pm 0.6$ & $20.1 \pm 0.3$ \\
$\mathrm{AIL}^{b}$ & {$[\%]$} & $16.2 \pm 0.8$ & $15.5 \pm 0.6$ & $15.7 \pm 0.8$ & $15.1 \pm 0.2$ \\
$\mathrm{ASL}^{c}$ & {$[\%]$} & $1.8 \pm 0.2$ & $2.5 \pm 0.3$ & $1.6 \pm 0.3$ & $2.2 \pm 0.1$ \\
Ash & {$[\%]$} & $0.7 \pm 0.2$ & $0.8 \pm 0.2$ & $8.4 \pm 0.3$ & $9.2 \pm 0.2$ \\
\hline
\end{tabular}

Note: ${ }^{a}$. XMG (xylan + mannan + galactan); ${ }^{b}$. AIL (acid insoluble lignin); ${ }^{c}$. ASL (acid soluble lignin). The data in the table show the mean value and standard deviation. Data in the table based on the oven-dried untreated biomass. Pretreatment conditions: $120 \mathrm{~h}, 90^{\circ} \mathrm{C}$, ammonia loading of $0.1 \mathrm{~g} \mathrm{NH}_{3} / \mathrm{g} \mathrm{ODW}$, moisture content of $50 \mathrm{wt} . \%$.

\subsection{Effect of Additional Xylanase on the Enzymatic Hydrolysis of LMAA-Treated Biomass}

The LMAA-treated biomass was saccharified by CTec2 (15 FPU/g-glucan) supplemented with various dosages of xylanase with volume ratio of $\mathrm{HTec} 2 / \mathrm{CTec} 2$ ranging from 0 to 10 and the digestibilities were determined by measurement of the released monomeric sugars. The effects of xylanase supplementation on glucan and xylan digestibilities of LMAA-treated corn stover and rice straw were summarized in Figure 2a,b. The results showed that HTec2 addition had a significant impact on CTec2's efficacy on the hydrolysis. Without additional xylanase, the glucan and xylan digestibility of LMAA-treated corn stover were $76.4 \%$ and $61.1 \%$, respectively, at $72 \mathrm{~h}$ of enzymatic hydrolysis. With the same enzyme loading, the glucan and xylan digestibility of LMAA-treated rice straw were $70.9 \%$ and $56.2 \%$, respectively. Glucan digestibilities of both LMAA-treated corn stover and rice straw increased to around $90 \%$ with sufficient xylanase supplementation, which was increased from $70.9 \%$ to $76.4 \%$ at $\mathrm{HTec} 2 / \mathrm{CTec} 2=0$. The highest glucan and xylan digestibility of LMAA-treated corn stover at HTec2/CTec 2 ratio of 10 were $91.1 \%$ and $73.7 \%$ respectively. Similarly, the corresponding values for LMAA-treated rice straw were $89.5 \%$ and $71.1 \%$. Glucan digestibility increased in proportion with the amount of xylanase addition for both corn stover and rice straw as shown in Figure 2. The results showed that xylanase not only hydrolyzed xylan but also enhanced glucan digestibility.

As observed in Figure 2a,b, it was speculated that there is a strong relationship between increases of xylan digestibility and glucan digestibility of LMAA-treated corn stover and rice straw. On the other hand, it can also be seen in Figure 2 that the enzymatic hydrolysis using 15 FPU/g-glucan of cellulase at $\mathrm{HTec} 2 / \mathrm{CTec} 2=0$ resulted in higher glucan and xylan digestibility $(76.4 \%$ and $61.1 \%)$ of LMAA-treated corn stover than those of LMAA-treated rice straw $(70.9 \%$ and $56.2 \%)$. The effect of pretreatment and enzymatic hydrolysis on the enzymatic saccharification of LMAA-treated corn stover was more evident than that of LMAA-treated rice straw. It should be noted that the ash content of rice straw was around $8.4 \%$, it is much higher than the ash content of corn stover which is only $0.7 \%$. During the enzymatic hydrolysis process, this ash would be ionized, and the cations transfer into the solution and affect the enzyme activity [8]. It may be one of the reasons that affect the enzymatic hydrolysis reaction. Though this idea has not attracted sufficient attention, Yu and Chen (2010) [8] reported that the ash cations of rice straw showed inhibitive effects on the activities of cellulase even at low concentration. Therefore, they suggested the removal of ash cations would be beneficial to the improvement of cellulase activity and increase the hydrolysis efficiency. On the other hand, the glucan content of rice straw is higher than that of corn, which can be beneficial for obtaining high ethanol yield from fermentation. Because the corn stover resulted in the higher saccharification yield; therefore, the following ethanol fermentation study was carried out using corn stover alone. 


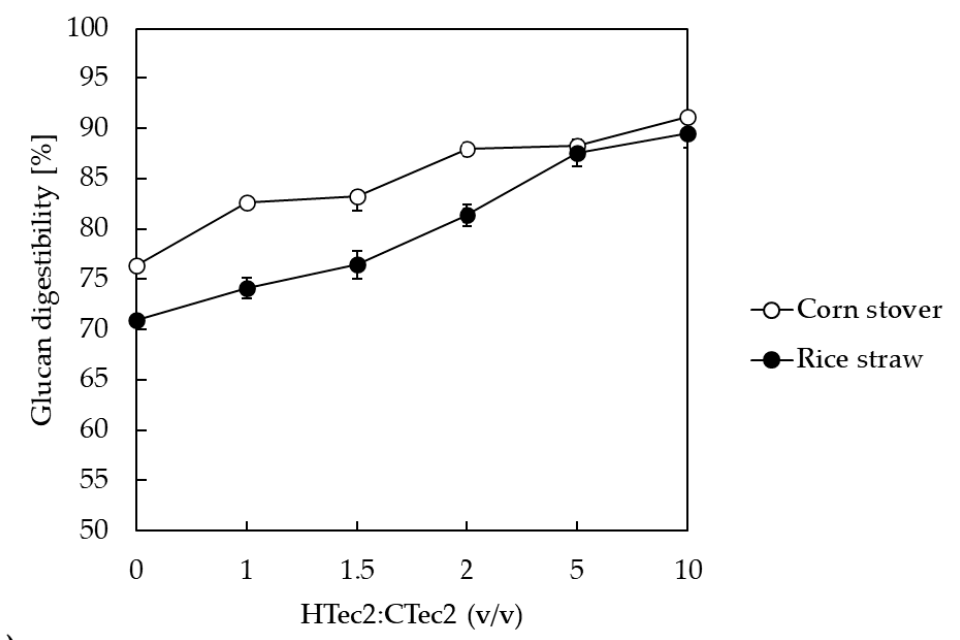

(a)

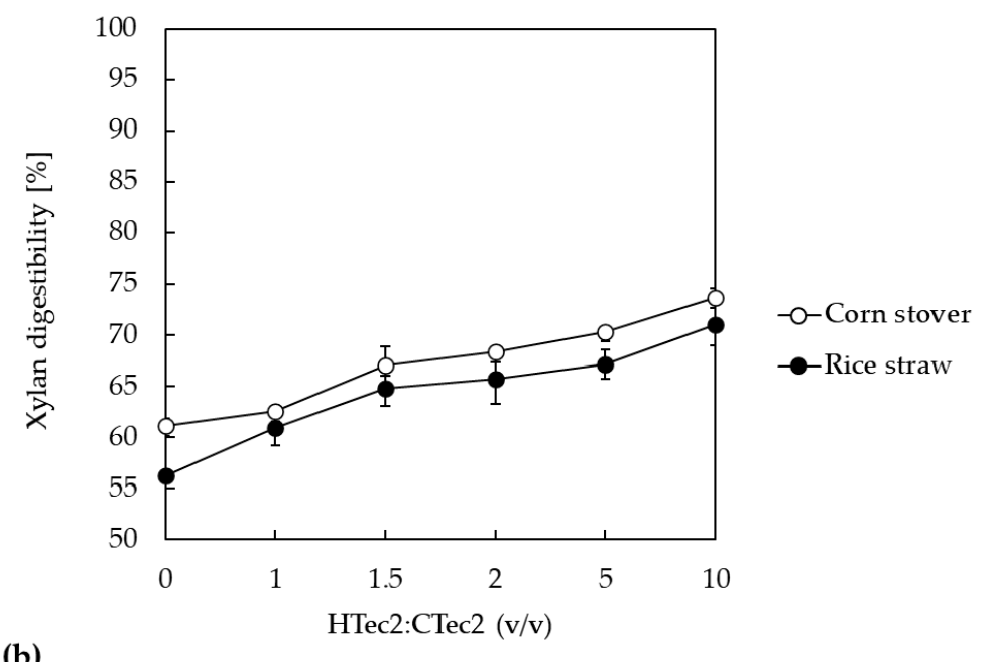

(b)

Figure 2. Effect of xylanase addition on (a) glucan digestibility and (b) xylan digestibility. Reaction condition: $120 \mathrm{~h}, 90{ }^{\circ} \mathrm{C}$, ammonia loading of $0.1 \mathrm{~g} \mathrm{NH}_{3} / \mathrm{g} \mathrm{ODW}$, moisture content of $50 \mathrm{wt.} \%$. Glucan and xylan digestibilities are $72 \mathrm{~h}$ digestibility.

\subsection{SSF and SSCF of LMAA-Treated Biomass}

The fermentation tests were conducted to compare the ethanol yield in SSF carried out with S. cerevisiae $\left(\mathrm{D}_{5} \mathrm{~A}\right)$ and SSCF carried out with recombinant E. coli (K011) using LMAA-treated corn stover under the pretreatment conditions of $90^{\circ} \mathrm{C}$ for $120 \mathrm{~h}$ as substrates. Figure $3 \mathrm{a}, \mathrm{b}$ showed the ethanol productions trends using S. cerevisiae $\left(\mathrm{D}_{5} \mathrm{~A}\right)$ and recombinant E. coli (K011). In all cases, use of recombinant E. coli (K011) achieved considerably higher ethanol yield than $S$. cerevisiae $\left(\mathrm{D}_{5} \mathrm{~A}\right)$; i.e., the ethanol production after $120 \mathrm{~h}$ of LMAA treated-corn stover of two strains were $13.5 \mathrm{~g} / \mathrm{L}(79.1 \%$ based on glucan only) and $16.7 \mathrm{~g} / \mathrm{L}\left(97.9 \%\right.$ based on glucan only) for S. cerevisiae $\left(\mathrm{D}_{5} \mathrm{~A}\right)$ and recombinant E. coli (K011), respectively. For SSCF using recombinant E. coli (K011), the ethanol production increased to $18.2 \mathrm{~g} / \mathrm{L}$ (106.1\% of total glucose loading) at $168 \mathrm{~h}$. The ethanol production of treated corn stover after $120 \mathrm{~h}$ was $14.7 \mathrm{~g} / \mathrm{L}\left(88.3 \%\right.$ based on glucan only) with S. cerevisiae $\left(\mathrm{D}_{5} \mathrm{~A}\right)$ and $19.8 \mathrm{~g} / \mathrm{L}(116.2 \%$ based on glucan only) with recombinant $E$. coli (K011), and the SSCF was carried out with recombinant $E$. coli (K011) which was further increased to $20.2 \mathrm{~g} / \mathrm{L}$ (118.4\% based on glucan only) at $168 \mathrm{~h}$. This indicated that the SSCF using recombinant E. coli (K011) produced more than $100 \%$ of theoretical maximum ethanol yield based on glucan only. The results confirmed that recombinant $E$. coli (K011) can consume both glucose and xylose and further convert them into ethanol effectively. 

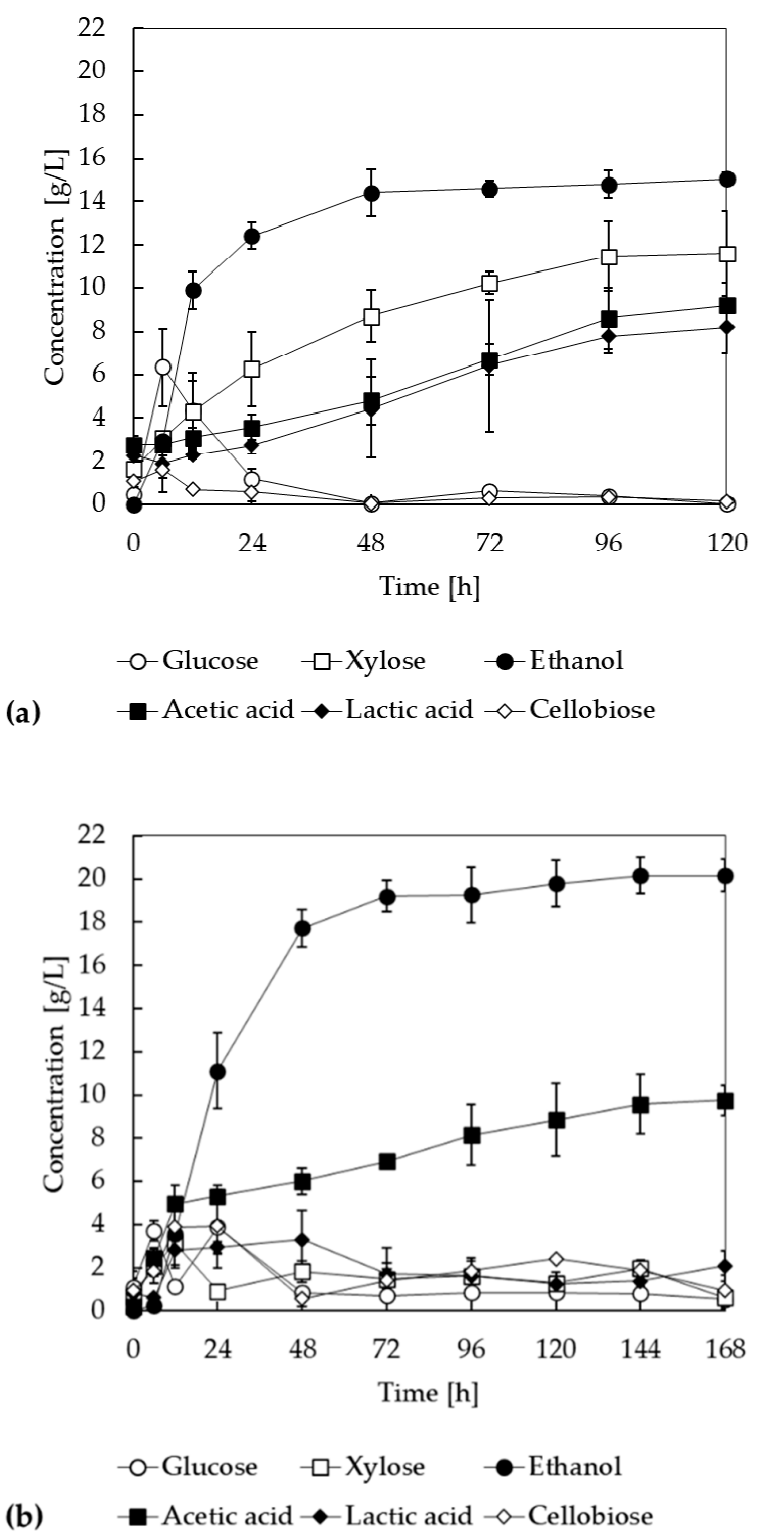

Figure 3. Ethanol production of LMAA-treated corn stover using (a) SSF and (b) SSCF. Reaction conditions: $120 \mathrm{~h}, 90{ }^{\circ} \mathrm{C}$, ammonia loading of $0.1 \mathrm{~g} \mathrm{NH}_{3} / \mathrm{g}$ ODW, moisture content of 50 wt. \%. enzyme ratio: HTec2:CTec2 volume ratio $=1.5$.

\subsection{Effect of Different Xylanase Dosages on Ethanol Productions in SSF and SSCF Processes Using LMAA-Treated Corn Stover}

As seen in the earlier section, additions of high dosage of xylanase resulted in high enzymatic saccharification yield of LMAA-treated biomass. However, high enzyme dosage can have a negative impact on the overall economics of the bioconversion process for bioethanol production because the cost of enzymes is very high. Therefore, further study was conducted to test the effect of xylanase dosage on ethanol production using LMAA-treated corn stover in SSF and SSCF reaction. The results are shown in Figure 4. Ethanol productivities in SSF and SSCF processes with no xylanase addition and with xylanase addition are pictorially represented in Figure 4a,b. In this test, LMAA-treated corn stover was used as the substrate. It was observed that the addition of HTec2 effectively enhanced both cellulose and hemicellulose hydrolyses, which resulted in conversion of sugars into ethanol at high yield, the same results were reported in our previous study [23]. It was reported that xylanase helps improving cellulase accessibility to the cellulosic part by reducing the hindrance caused by the 
resilient hemicellulose layer on the cellulose microfibril. Ethanol production with HTec2/CTec2 = 1.5 for LMAA-treated corn stover was increased by $24.5 \%$ (from 11.2 to $15.2 \mathrm{~g} / \mathrm{L}$ ) for SSF and 10.0\% (from 18.5 to $20.1 \mathrm{~g} / \mathrm{L}$ ) for SSCF, respectively. It proved that there was no ethanol produced from xylose in the SSF by using $S$. cerevisiae $\left(D_{5} A\right)$. Meanwhile, the ethanol yield in SSF was increased when xylanase was added, which was assumed that hydrolysis of hemicellulose was enhanced by added xylanase, then resulting in synergistic effect on cellulose hydrolysis. However, no increase of ethanol production was observed when enzyme xylanase dosages were increased further (HTec2/CTec2 ratio $>1.5(v / v)$ ) in both SSF and SSCF tests. On the contrary, unusual phenomena was observed; i.e., when the $\mathrm{HTec} 2 / \mathrm{CTec} 2$ ratios increased up to $10(v / v)$, ethanol yields were reduced substantially from $118.0 \%$ to $87.9 \%$ for SSCF and $89.9 \%$ to $76.3 \%$ for SSF (Figure 4). The same observation was reported by Tomás-Pejó et al., (2009) [25] that viable cell count was affected by the enzyme concentration in the broth due to the stabilizing additives such as sorbitol or glycerol in the crude enzyme, which leads to a decrease in the ethanol production.

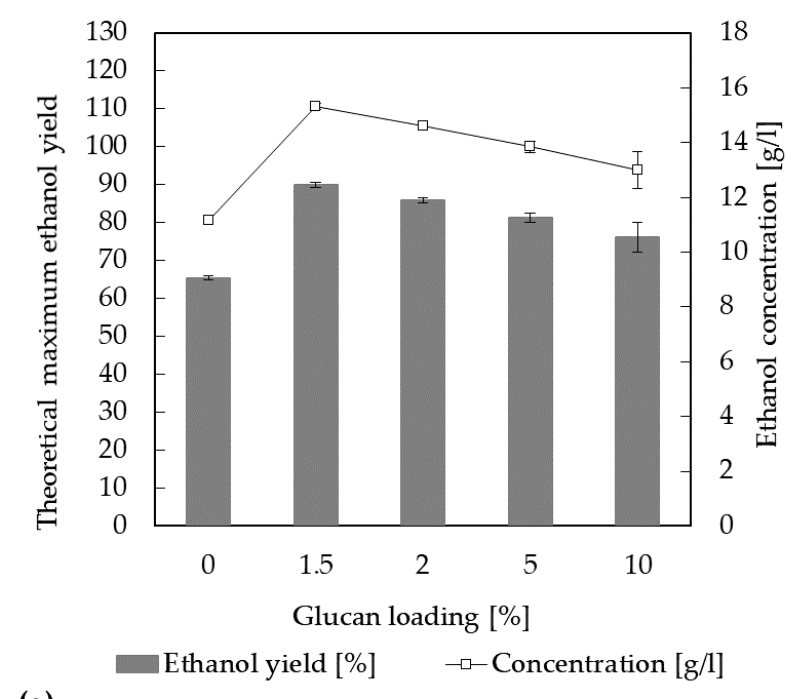

(a)

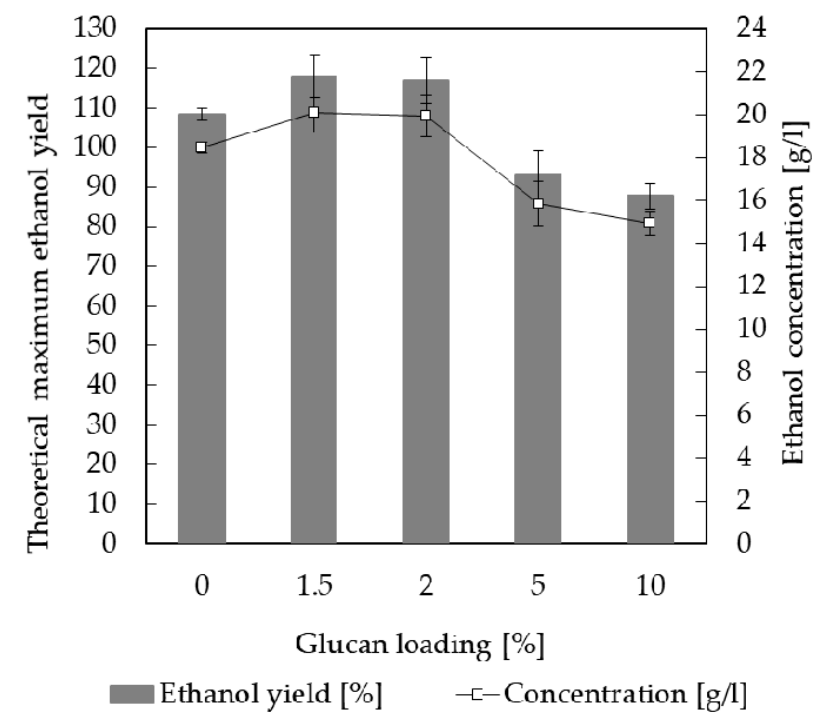

(b)

Figure 4. Effect of xylanase loading on ethanol production using LMAA-treated corn stover (a) SSF and (b) SSCF. Reaction conditions: $120 \mathrm{~h}, 90^{\circ} \mathrm{C}$, ammonia loading of $0.1 \mathrm{~g} \mathrm{NH}_{3} / \mathrm{g}$ ODW, moisture content of 50 wt.\%. 
Therefore, we conducted this test to determine whether xylose concentration has a negative effect on ethanol production. The concentration of xylose in $100 \mathrm{~mL}$ working solution were $0.42 \%, 1.42 \%$, $2.42 \%$ and were chosen according to the xylanase in the biomass used in the previous SSF and SSCF.

In the SSF mode, the ethanol yields were stable at $82 \%$ (around $15 \mathrm{~g} / \mathrm{L}$, Figure $5 \mathrm{a}$ ) when the xylose concentration increased from $1.42 \%$ to $2.42 \%$. However, in the SSCF, ethanol yield was increased by $23.2 \%$ (from 17.8 to $22.1 \mathrm{~g} / \mathrm{L}$ ), as the xylose loading increased from $0.42 \%$ to $1.42 \%$.On the contrary, unusual phenomena was observed; i.e., when the xylose concentration increased from $1.42 \%$ to $2.42 \%$ ethanol yields were reduced substantially from $121.2 \%$ to $118.4 \%$ (from 22.1 to $21.6 \mathrm{~g} / \mathrm{L}$, Figure $5 \mathrm{~b}$ ). As a result, it was found that xylose concentration in the fermentation has no effect on SSF mode, but has a negative effect on ethanol yield for the SSCF.

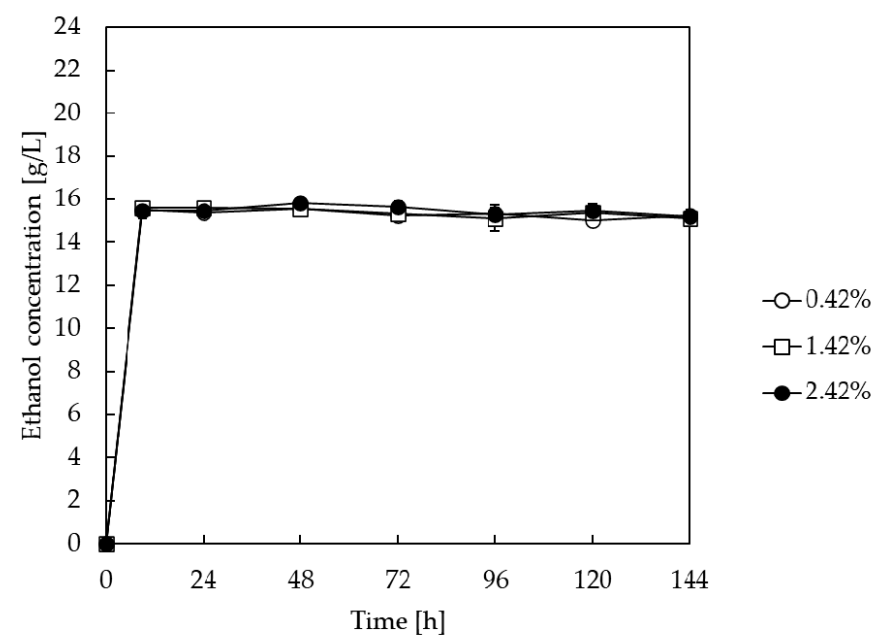

(a)

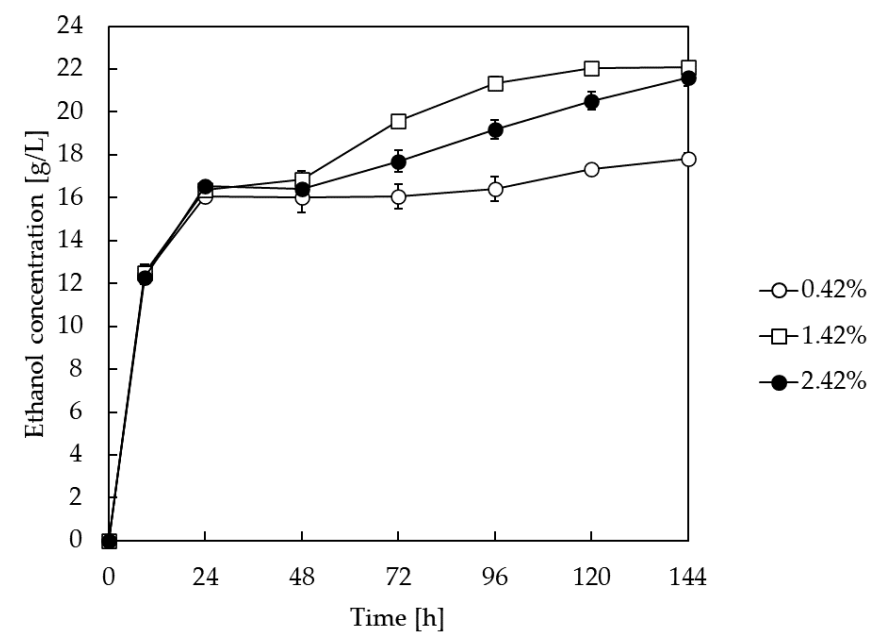

(b)

Figure 5. Effect of xylose concentration in (a) SSF and (b) SSCF. Pretreatment conditions: $120 \mathrm{~h}, 90^{\circ} \mathrm{C}$, ammonia loading of $0.1 \mathrm{~g} \mathrm{NH}_{3} / \mathrm{g}$ ODW, moisture content of $50 \mathrm{wt} . \%$.

\subsection{High-Solid Fermentation Using Fed-Batch SSF and SSCF}

Because the corn stover is fluffy and absorbs a large amount of water, it is difficult to increase initial solid loading higher than $20 \%(w / v)$ in the bioreactor. In general, a fermentation at high initial solid loading encounters problems such as poor agitation or shaking and low ethanol production yield due to high viscosity and poor mass transfer. 
As the solid loading increases, the higher ethanol concentration can be achieved at the end of fermentation, which can be beneficial to the downstream process, such as product recovery using distillation [26]. This can have a positive impact on total ethanol production cost because the smaller size equipment can be used and the energy cost for ethanol concentration and process water recycle can be reduced [27]. The fed-batch fermentation can reduce the viscosity even at high solid loading; therefore, it can overcome poor mass transfer and mixing problem. SSF and SSCF tests using LMAA-treated corn stover were conducted at $2.0 \%$ to $7.0 \%(w / v)$ glucan loading to evaluate the effect of HTec 2 addition on ethanol fermentation. The results showed that $2.0 \%$ initial glucan loading yielded the highest ethanol production, but the ethanol concentration was very low (Figure 6). In the fed-batch SSF, final ethanol concentration was increased from 10.9 to $31.6 \mathrm{~g} / \mathrm{L}$ according to the increase of glucan loading from $2.0 \%$ to $7.0 \%(w / v)$; i.e., the highest ethanol yield ( $96.3 \%$ of theoretical maximum) was obtained at $2.0 \%$ glucan loading. The ethanol yield was decreased by $7.4 \%$ (from $96.3 \%$ to $88.9 \%$ ), as the glucan loading increased from $2.0 \%$ to $7.0 \%$. In the SSCF mode, the ethanol concentration increased from 14.0 to $34.8 \mathrm{~g} / \mathrm{L}$. However, substantial decrease of ethanol production yield (from $116.6 \%$ to $92.4 \%$ ) was observed at higher glucan loading. Similar observation was reported by Liu and Chen for ethanol yield with the increase of solid loading [28].

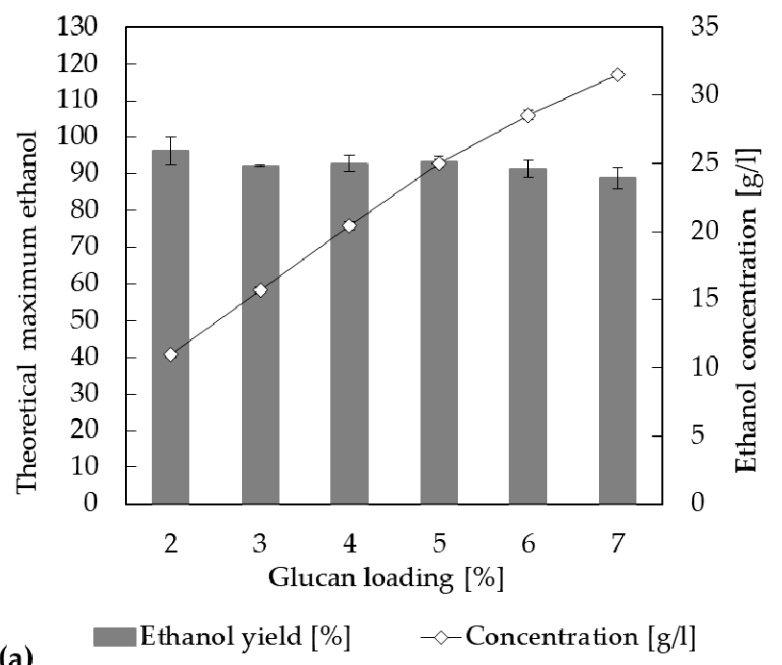

(a)

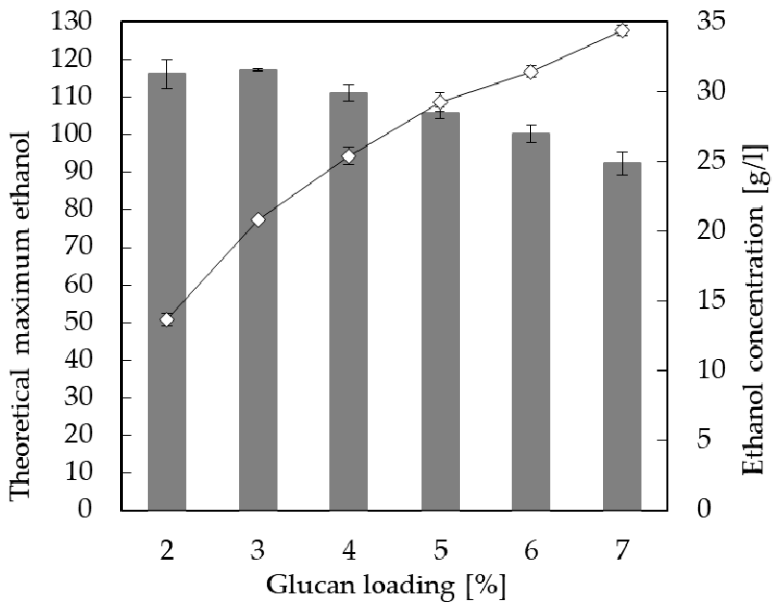

(b)

Figure 6. High-solid fed-batch fermentation using LMAA-treated corn stover (a) SSF and (b) SSCF. Reaction conditions: $120 \mathrm{~h}, 90^{\circ} \mathrm{C}$, ammonia loading of $0.1 \mathrm{~g} \mathrm{NH}_{3} / \mathrm{g}$ ODW, moisture content of $50 \mathrm{wt} \%$. 


\subsection{Selection of Inoculum Size for Ethanol Production in SSCF}

Inoculum size is also a very important factor to improve the economics of the process, because it is more costly to input a large size of inoculum than to a small inoculum. In this study, a suitable inoculum concentration and size for effective ethanol production in the SSCF using LMAA-treated corn stover was studied. Six different inoculum concentrations (OD of 0.0625, 0.125, 0.25, 0.5, 1.0, and 2.0) were used in this test. Figure 7 showed the ethanol production of SSCF using four different inoculum sizes of recombinant E. coli (K011). The results showed that 0.0625 of OD inoculum size resulted in the lowest ethanol yield of $17.1 \mathrm{~g} / \mathrm{L}$ after $72 \mathrm{~h}$ of the SSCF run. As shown in Table 2, ethanol production was significantly increased $(p=0.03)$ as the amount of the inoculum was raised from OD $=0.0625$ to $\mathrm{OD}=0.25$. Maximum ethanol yield was achieved at $\mathrm{OD}=0.25$ inoculum, and ethanol concentration reached at $20.5 \mathrm{~g} / \mathrm{L}$ after $72 \mathrm{~h}$ of the fermentation. On the other hand, when OD higher than 0.25 (OD of $0.5,1.0$, and 2.0), the ethanol production slightly decreased $(19.7,19.3$, and $18.9 \mathrm{~g} / \mathrm{L}$ ). This result confirmed that increasing the recombinant E. coli (K011) input (OD > 0.25) resulted in reduced ethanol yields as more sugar is required and consumed for cell growth. On the contrary, the smaller inoculum size required less sugar, but the bioconversion reaction rate was reduced. This result agreed with what was report by Dada et al., 2012 [29] and Ferchichi et al., 2008 [30] where the strains use the energy and carbon from the substrate to use in the microbial growth. Therefore, the higher inoculums concentration lead to the higher energy and carbon to be consumed, and this results in the negative impact in the fermentation process.

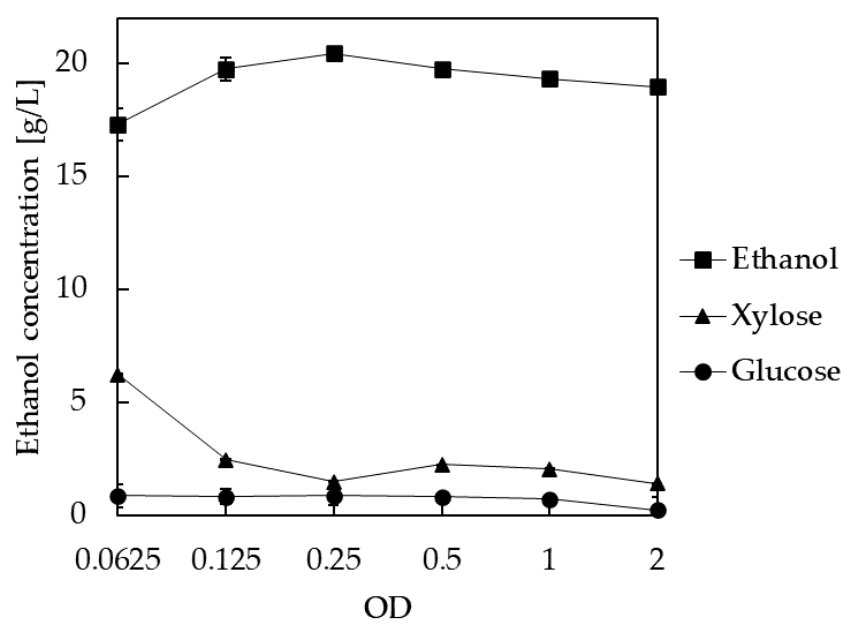

Figure 7. Effects of inoculum size to the ethanol yield in the SSCF using LMAA-treated corn stover. Reaction conditions: $120 \mathrm{~h}, 90^{\circ} \mathrm{C}$, ammonia loading of $0.1 \mathrm{~g} \mathrm{NH}_{3} / \mathrm{g}$ ODW, moisture content of $50 \mathrm{wt} . \%$.

Table 2. The ANOVA analysis of the effect of inoculum sizes on ethanol yield in SSCF.

\begin{tabular}{ccccccc}
\hline Source of Variation & SS & DF & MS & $\boldsymbol{F}$ & $p$-Value & $\boldsymbol{F}$ crit \\
\hline Between Groups & 12.35 & 5 & 2.47 & 5.34 & 0.03 & 4.39 \\
Within Groups & 2.78 & 6 & 0.46 & & & \\
Total & 15.12 & 11 & & & & \\
\hline
\end{tabular}

Note: SS: sum of the squares; MS: mean square; DF: degrees of freedom (=1).

\section{Conclusions}

It was found that increase of LMAA-pretreatment time from 24 to $120 \mathrm{~h}$, maintaining temperature at $90{ }^{\circ} \mathrm{C}$ (ammonia loading of $0.1 \mathrm{~g} \mathrm{NH}_{3} / \mathrm{g}$ ODW) did not result in significant improvement on enzymatic digestibilities of corn stover and rice straw. With LMAA-treated biomass, the addition of HTec2 xylanase at high dosage (HTec2/CTec2 > 1.5) showed the significant effect on enzymatic saccharification, i.e., glucan digestibility for LMAA-treated corn stover was increased from $76.4 \%$ to 
91.1\% with $15 \mathrm{FPU} / \mathrm{g}$-glucan. However, it was interesting that it resulted in a decrease of ethanol production, i.e., ethanol yield of treated corn stover was decreased from $89.9 \%$ to $76.3 \%$ for SSF and from $118.0 \%$ to $87.9 \%$ for SSCF. The results showed that released xylose has no effect on SSF but has negative effect on ethanol yield for the SSCF.

In a fed-batch fermentation mode, ethanol yield was decreased as the glucan loading increased from $2.0 \%$ to $7.0 \%$, the ethanol production of SSF and SSCF was $88.9 \%$ and $94.2 \%$, respectively (based on glucan loading) at $7.0 \%$ final glucan loading. Highest ethanol production $(20.5 \mathrm{~g} / \mathrm{L})$ was achieved with inoculum size of OD of 0.25 .

Author Contributions: S.H.P. and T.T.H.P. equally conducted all experiments, summarized the data, and drafted a manuscript. T.H.K. designed overall study and experiments, interpreted the results, wrote a manuscript, and finalized the manuscript. All authors have read and agreed to the published version of the manuscript.

Funding: This work was supported by the R\&D program of Korea Institute of Energy Technology Evaluation and Planning (KETEP) grant funded by the Ministry of Trade, Industry \& Energy (MOTIE), Korea (No. 20183030092080).

Conflicts of Interest: The authors declare no conflict of interest.

\section{References}

1. Uihlein, A.; Schebek, L. Environmental impacts of a lignocellulose feedstock biorefinery system: An assessment. Biomass Bioenergy 2009, 33, 793-802. [CrossRef]

2. Sarkar, N.; Ghosh, S.K.; Bannerjee, S.; Aikat, K. Bioethanol production from agricultural wastes: An overview. Renew. Energy 2012, 37, 19-27. [CrossRef]

3. Zhang, C.; Chen, H.; Pang, S.; Su, C.; Lv, M.; An, N.; Wang, K.; Cai, D.; Qin, P. Importance of redefinition of corn stover harvest time to enhancing non-food bio-ethanol production. Renew. Energy 2020, 146, 1444-1450. [CrossRef]

4. Luo, W.; Wang, J.; Liu, X.B.; Li, H.; Pan, H.; Gu, Q.; Yu, X. A facile and efficient pretreatment of corncob for bioproduction of butanol. Bioresour. Technol. 2013, 140, 86-89. [CrossRef]

5. Liu, X.; Yu, X. Enhancement of butanol production: From biocatalysis to bioelectrocatalysis. J. Am. Chem. Soc. 2020, 5, 867-878. [CrossRef]

6. Ben-Iwo, J.; Manovic, V.; Longhurst, P. Biomass resources and biofuels potential for the production of transportation fuels in Nigeria. Renew. Sustain. Energy Rev. 2016, 63, 172-192. [CrossRef]

7. Sjostrom, E. Wood Chemistry Fundamentals and Applications, 2nd ed.; Academic Press: New York, NY, USA, 1993.

8. Yu, B.; Chen, H.Z. Effect of the ash on enzymatic hydrolysis of steam-exploded rice straw. Bioresour. Technol. 2010, 101, 9114-9119. [CrossRef]

9. Palonen, H. Role of Lignin in the Enzymatic Hydrolysis of Lignocellulose. Ph.D. Thesis, Aalto University, Espoo, Finland, April 2004.

10. Naik, S.N.; Goud, V.V.; Rout, P.K.; Dalai, A.K. Production of first and second generation biofuels: A comprehensive review. Renew. Sustain. Energy Rev. 2010, 14, 578-597. [CrossRef]

11. Limayem, A.; Ricke, S.C. Lignocellulosic biomass for bioethanol production: Current perspectives, potential issues and future prospects. Prog. Energy Combust. Sci. 2012, 38, 449-467. [CrossRef]

12. Tu, W.C.; Hallett, J.P. Recent advances in the pretreatment of lignocellulosic biomass. Curr. Opin. Green. Sustain. 2019, 20, 11-17. [CrossRef]

13. Bhatiaa, S.K.; Jagtapc, S.S.; Bedekarc, A.A.; Bhatiae, R.K.; Patelf, A.K.; Pantg, D.; Banuh, J.R.; Raoc, C.V.; Kimi, Y.G.; Yang, Y.H. Recent developments in pretreatment technologies on lignocellulosic biomass: Effect of key parameters, technological improvements, and challenges. Bioresour. Technol. 2020, 300, 122724. [CrossRef] [PubMed]

14. Sainz, M.B. Commercial cellulosic ethanol: The role of plant-expressed enzymes. In Vitro Cell. Dev. Biol. Plant 2009, 45, 314-329. [CrossRef]

15. Kim, H.; Kim, J.S.; Sunwoo, C.; Lee, Y.Y. Pretreatment of corn stover by aqueous ammonia. Bioresour. Technol. 2003, 90, 39-47. [CrossRef]

16. Kim, T.H.; Lee, Y.Y. Pretreatment and fractionation of corn stover by ammonia recycle percolation process. Bioresour. Technol. 2005, 96, 2007-2013. [CrossRef] [PubMed] 
17. Yoo, C.G.; Nghiem, P.N.; Hicks, K.B.; Kim, T.H. Pretreatment of corn stover using low-moisture anhydrous ammonia (LMAA) process. Bioresour. Technol. 2011, 102, 10028-10034. [CrossRef]

18. Cayetano, R.D.; Kim, T.H. Effects of low moisture anhydrous ammonia (LMAA) Pretreatment at controlled ammoniation temperatures on enzymatic hydrolysis of corn stover. Appl. Biochem. Biotechnol. 2017, 181, 1257-1269. [CrossRef]

19. Hu, J.; Arantes, V.; Saddler, J.N. The enhancement of enzymatic hydrolysis of lignocellulosic substrates by the addition of accessory enzymes such as xylanase: Is it an additive or synergistic effect? Biotechnol. Biofuels 2011, 4, 36-48. [CrossRef]

20. Gupta, R.; Kim, T.H.; Lee, Y.Y. Substrate dependency and effect of xylanase supplementation on enzymatic hydrolysis of ammonia-treated biomass. Appl. Biochem. Biotechnol. 2008, 148, 59-70. [CrossRef]

21. Hames, B.; Ruiz, R.; Scarlata, C.; Sluiter, J.; Templeton, D.; Crocker, D. Determination of Structural Carbohydrates and Lignin in Biomass; NREL/TP-510-42618; National Renewable Energy Laboratory (NREL): Golden, CO, USA, 2008.

22. Ghose, T.K.; Bisaria, V.S. Measurement of hemicellulose activities; Part 1: Xylanases. Pure Appl. Chem. 1987, 59, 1739-1752. [CrossRef]

23. Selig, M.; Weiss, N.; Ji, Y. Enzymatic Saccharification of Lignocellulosic Biomass; NREL/TP-510-42629; National Renewable Energy Laboratory (NREL): Golden, CO, USA, 2008.

24. Dowe, N.; McMillan, J. SSF Experimental Protocols-Lignocellulosic Biomass Hydrolysis and Fermentation; NREL/TP-510-42630; National Renewable Energy Laboratory (NREL): Golden, CO, USA, 2008.

25. Tomás-Pejó, E.; García-Aparicio, M.; Negro, M.J.; Oliva, J.M.; Ballesteros, M. Effect of different cellulase dosages on cell viability and ethanol production by Kluyveromy cesmarxianus in SSF processes. Bioresour. Technol. 2009, 100, 890-895. [CrossRef]

26. Modenbach, A.A.; Nokes, S.E. The use of high-solids loadings in biomass pretreatment-a review. Biotechnol. Bioeng. 2012, 109, 1430-1442. [CrossRef] [PubMed]

27. Liu, Z.H.; Qin, L.; Zhu, J.Q.; Li, B.Z.; Yuan, Y.J. Simultaneous saccharification and fermentation of steam-exploded corn stover at high glucan loading and high temperature. Biotechnol. Biofuels 2014, 7, 167-182. [CrossRef]

28. Liu, Z.H.; Chen, H.Z. Simultaneous saccharification and co-fermentation for improving the xylose utilization of steam exploded corn stover at high solid loading. Bioresour. Technol. 2016, 201, 15-26. [CrossRef] [PubMed]

29. Dada, O.; Kalil, M.S.; Yusoff, W.M.W. Effect of inoculum and substrate concentrations in anaerobic fermentation of treated rice bran to acetone, butanol and ethanol. Bacteriol. J. 2012, 2, 79-89. [CrossRef]

30. Ferchichi, M.; Crabbe, E.; Hintz, W.; Gil, G.H.; Almadid, A. Influence of culture parameters on biological hydrogen production by Clostridium Saccharoperbutylacetonicum ATCC 27021. World J. Mcrob. Biotechnol. 2005, 21, 855-866. [CrossRef]

(C) 2020 by the authors. Licensee MDPI, Basel, Switzerland. This article is an open access article distributed under the terms and conditions of the Creative Commons Attribution (CC BY) license (http://creativecommons.org/licenses/by/4.0/). 